\title{
Out-patient rehabilitation improves activities of daily living, quality of life and exercise tolerance in chronic obstructive pulmonary disease
}

\author{
K.E. Bendstrup, J. Ingemann Jensen, S. Holm, B. Bengtsson
}

Out-patient rehabilitation improves activities of daily living, quality of life and exercise tolerance in chronic obstructive pulmonary disease. K.E. Bendstrup, J. Ingemann Jensen, S. Holm, B. Bengtsson. CERS Journals Ltd 1997.

ABSTRACT: The purpose of this study was to investigate the effects on activities of daily living, quality of life, and exercise tolerance of a comprehensive out-patient rehabilitation programme for patients with moderate-to-severe chronic obstructive pulmonary disease.

In this randomized and controlled trial, the main outcome measures were Activiies of Daily Living (ADL) score, York Quality of Life Questionnaire (YQLQ) score, Chronic Respiratory Disease Questionnaire (CRDQ) score, 6 min walking distance (6MWD), forced expiratory volume in one second (FEV1), and forced vital capacity (FVC). The rehabilitation programme included physical training, occupational therapy, education, and smoking cessation therapy, and lasted for 12 weeks. The patients were evaluated at entry, halfway through, and at the end of the programme. Follow-up was at 24 weeks.

Forty seven patients were recruited, and 16 in each group completed the trial. There were significant differences in the improvements in ADL and CRDQ between the control and the treatment groups at 12 and 24 weeks, and at 24 weeks, respectively. At 6, 12 and 24 weeks, improvements in the 6MWD were 21.6 versus 79.8, 36.1 versus 113.1 and 21.4 versus 96.2 for control and treatment groups, respectively $(\mathrm{p}<0.004)$. A correlation matrix showed only ADL and 6MWD to be significantly correlated; the matrix was also used to validate the translated questionnaires. The programme required 124 staff-hours in total.

An inexpensive, comprehensive out-patient rehabilitation programme can produce long-term improvement in activities of daily living, quality of life, and exercise tolerance in patients with moderate-to-severe chronic obstructive pulmonary disease.

Eur Respir J 1997; 10: 2801-2806.
Dept of Medicine, Centralsygehuset, Esbjerg, Denmark.

Correspondence: K.E. Bendstrup

Dept of Medicine

Centralsygehuset

DK 6700 Esbjerg

Denmark

Keywords: Activities of daily living chronic obstructive pulmonary disease controlled, randomized design

quality of life

rehabilitation

six minute walking test

Received: August 11995

Accepted after revision September 71997

This study was supported by grants from The National Association Against Lung Diseases and The Foundation for Medical Research of Ribe, Ringkøbing, and Southern Jutland Counties.
Rehabilitation programmes for patients with chronic obstructive pulmonary disease (COPD) have been shown to have a number of benefits, such as fewer hospital admissions, reduced dyspnoea, improved work tolerance, improved self-esteem, improved sense of well-being, and greater freedom in the activities of daily living. These improvements have largely been achieved with no change in pulmonary function [1-11].

Only a few of these studies have included a control group, many were in-patient programmes, and nearly all have focused mainly on a specific aspect of pulmonary rehabilitation: exercise training (respiratory muscle training, upper limb, lower limb, or combination training), education, occupational therapy, or cessation of smoking.

The purpose of this study was to set-up and evaluate, using a controlled, randomized design, a comprehensive out-patient programme for patients with COPD, with emphasis upon improvements in activities of daily living, quality of life, and exercise tolerance. The programme was specifically designed to require the modest and economic resources available at most community hospitals.

\section{Methods}

\section{Patients}

From hospital records of the last 5 yrs, 140 patients diagnosed with either chronic obstructive bronchitis or emphysema were invited for evaluation. Eighty five were interviewed and 47 were found to satisfy the following inclusion criteria: 1) forced expiratory volume in one second (FEV1) between $25 \%$ and $55 \%$ of the predicted value for age, gender, and height [12]; 2) Tiffenau index (FEV1/forced vital capacity (FVC) ratio) less than 70\% [12]; and 3) stable condition for at least 4 weeks: no change in exercise status, sputum colour 
and quantity, or changes in medication. The exclusion criteria were: 1) heart disease (moderate or severe ischaemic heart disease, acute myocardial infarction within 3 months, cardiomyopathy, and valvular heart disease); 2) musculoskeletal disease limiting exercise; and 3) intermittent claudication limiting exercise. The study was approved by the regional Ethics Committee, and informed signed consent was obtained from all patients.

The patients were randomly allocated to either an intervention or a control group. The patients in the control group were told at inclusion that they would be offered an active programme at the end of the study, if the study showed significant effect. For both groups, the study did not interfere with the patients' usual follow-up pattern. Exacerbations were, thus, cared for by the primary physician; no exacerbation was severe enough to cause interruption of the training.

\section{Intervention}

The intervention programme lasted 12 weeks. The programme consisted of the following components.

Exercise training. The patients trained together at the hospital for $1 \mathrm{~h}$, three times a week for 12 weeks. The sessions were conducted by a physiotherapist with support from an auxilliary nurse. Strength training, both of upper and lower limbs and back muscles, was accomplished using tubular latex bands (length $1.5 \mathrm{~m}$, diameter $1 \mathrm{~cm})$. For the stronger participants the bands were doubled. Backwards walking, crossed/uncrossed sideways walking, and running forwards and backwards were used to improve co-ordination and balance. Stair climbing was used for endurance training. A few patients trained with a skipping rope. Stretching constituted an additional part of the programme. The physiotherapist individualized the training, according to the needs and resources of each patient. The participants were strongly encouraged to reach their maximum tolerable exercise level. Except for the elastic bands, the training required no special equipment. The patients were encouraged to train at home and to continue training after the intervention period.

Occupational therapy. Groups of four to five patients with similar Activities of Daily Living (ADL) scores (see below) at inclusion were formed. An occupational therapist had two lessons with each group, teaching techniques to overcome impairment of the everyday tasks listed by the ADL questionnaire.

Education. During 12 sessions, the patients were taught the anatomy of the lungs, pathophysiology and complications of COPD, and treatment modalities, with special emphasis upon the proper administration, dosage and side-effects of the normally used drugs. Special consideration was given to correct inhalation techniques, and how to cope with acute dyspnoea. A psychologist told the participants about psychological problems associated with COPD, a social worker informed about socioeconomic problems, and a dietician taught about nutrition (one lesson each).

Smoking cessation. Participants wishing to stop smoking were offered free transdermal nicotine patches, ac- cording to established recommendations $[13,14]$. Benefits and problems of smoking cessation were taught at the beginning of the programme, with two reinforcement sessions halfway through the programme. A folder with advice was also available. A physician and an occupational therapist were in charge of sessions, the latter offering practical alternatives to smoking.

\section{Assessment}

Assessments were performed at inclusion and after 6 , 12 and 24 weeks ( 12 weeks after the end of the programme). All assessments were performed in the late afternoons. The questionnaires were translated into Danish.

Activities of Daily Living score. A questionnaire specifically designed for patients with chronic pulmonary diseases was used [15]. It consisted of 41 questions covering: eating, personal care, dressing, bathing, going to the toilet, preparing meals, cleaning, washing clothes, shopping, social activities and work. Except at inclusion, the patients answered this questionnaire at the hospital, with the investigators available for help.

Chronic Respiratory Disease Questionnaire (CRDQ) score [16]. This questionnaire measures: dyspnoea, fatigue, emotional function, and mastery of the disease and its effects. [16]. The questionnaire was administered as a structured interview, and all interviews were performed by the same investigator. Previous scores were available to the patient at each interview.

The York Quality of Life Questionnaire (YQLQ) score [17]. This questionnaire measures quality of life on a scale from 0 (dead) to 1 (perfect health), allowing calculation of quality-of-life adjusted years. The questionnaire is self-explanatory and was answered at the hospital. The investigators were available for help.

Further assessments. During the 6 min walking distance (6MWD) along a flat hospital corridor $(50 \mathrm{~m})$, each patient was paced to cover the maximum possible distance, pausing for breath if necessary. No training sessions were included. Blood pressure, pulse rate, and arterial blood tensions were measured before and after 12 weeks. At 6 and 24 weeks, pulse oximetry (Pulsox 8; Minolta Camera Co. Ltd, Japan) was performed before, during and after exercise.

To monitor the success of smoking cessation therapy, the patients were asked to exhale through a carbon monoxide analyser (Mini Smokerlyzer; Bedfont Technical Instruments Ltd, UK). Their tobacco consumption was also recorded.

FEV1 and FVC were recorded from the best of three forced volume-time curves (Vitalograph ${ }^{\circledR}$; Vitalograph Ltd, UK). Most patients needed to use bronchodilators in order to get to the hospital; all tests within an individual patient were standardized, whether performed pre- or postbronchodilator. The patients measured peak expiratory flow (PEF) with a mini peak flow meter (Vitalograph®), twice daily. Patient attendance was monitored at each session. The number of staff working hours was recorded. 


\section{Statistical analysis}

Statistical analysis was performed using StatView for MacIntosh and BMDP for PC (1987 edition). All continuous data were analysed using the unpaired t-test on the difference between the baseline value at entry into the study and the value at a given later time. All discrete data were analysed using the Chi-squared test. The level of significance was set at $5 \%$.

A matrix of overall (0th order) and 4th order partial correlations between all six main outcomes was calculated. The purpose of including partial correlations was to arrive at the true bivariate (i.e. corrected for the simultaneous correlations with other variables) correlations between FEV1, FVC, CRDQ, YQLQ, ADL and 6MWD. It also provided information regarding the validity of the Danish translations of the questionnaires.

\section{Results}

The 47 eligible patients were randomized. Five patients failed to attend and did not provide a reason, leaving 22 and 20 patients in the control and the intervention group, respectively. Ten patients did not complete the programme. Of the four patients in the intervention group who did not complete the programme, one died in her home (as far as could be ascertained the cause of death was unrelated to the rehabilitation programme; no autopsy was performed), one was admitted for acute abdominal surgery and two elected to drop out. In the control group: one patient was excluded due to myocardial infarction and five patients elected to drop out.

Therefore, 16 patients in each group completed the programme. The average attendance rate for the intervention group was $78 \%$.

Table 1 presents the demographic data for the patients studied. There were no significant differences between the two groups for any of the variables listed.

The ADL score improved only in the intervention group, and the difference in improvements between the two groups reached statistical significance at 12 and 24 weeks (table 2). The improvements for the intervention

Table 1. - Demographic data of the subjects

\begin{tabular}{|c|c|c|}
\hline & Treatment & Control \\
\hline $\operatorname{Sex} F / M$ & $7 / 9$ & $7 / 9$ \\
\hline Age yrs & $64 \pm 3$ & $65 \pm 2$ \\
\hline Smokers/nonsmokers & $9 / 7$ & $7 / 9$ \\
\hline FEV1 $\quad L \cdot \min ^{-1}$ & $1.02 \pm 0.06$ & $1.04 \pm 0.07$ \\
\hline FVC L & $2.05 \pm 0.12$ & $2.08 \pm 0.15$ \\
\hline $\mathrm{Pa}_{\mathrm{a}, \mathrm{O}_{2}} \mathrm{kPa}$ & $10.78 \pm 0.41$ & $10.06 \pm 0.49$ \\
\hline $\mathrm{Pa}_{\mathrm{a}, \mathrm{CO}_{2}} \mathrm{kPa}$ & $5.23 \pm 0.15$ & $5.16 \pm 0.21$ \\
\hline $\mathrm{Sa}_{\mathrm{a}, \mathrm{O}_{2}} \%$ & $95 \pm 0.6$ & $94 \pm 1.0$ \\
\hline 6MWD m & $316 \pm 33.7$ & $339 \pm 27.9$ \\
\hline CRDQ score & $86 \pm 4.9$ & $83 \pm 3.3$ \\
\hline YQLQ score & $0.94 \pm 0.02$ & $0.96 \pm 0.01$ \\
\hline ADL score & $127.6 \pm 9.5$ & $135.0 \pm 6.2$ \\
\hline
\end{tabular}

Values are presented as mean \pm SEM. F: female; M: male; FEV1: forced expiratory volume in one second; FVC: forced vital capacity; $\mathrm{Pa}, \mathrm{O}_{2}$ : arterial oxygen tension; $\mathrm{Pa}_{\mathrm{a}} \mathrm{CO}_{2}$ : arterial carbon dioxide tension; $\mathrm{Sa}_{\mathrm{a}} \mathrm{O}_{2}$ : arterial oxygen saturation; $6 \mathrm{MWD}$ : 6 min walking distance; CRDQ: Chronic Respiratory Disease Questionnaire; YQLQ: York Quality of Life Questionnaire; ADL: Activities of Daily Living. group fell mainly in the following areas: personal care, house cleaning, and shopping.

The CRDQ score for the control group changed little during the programme. The scores for the intervention group showed a trend towards improvement with time, and the difference between the two groups was statistically significant on follow-up (table 3) at 24 weeks.

YQLQ score improved in the intervention group, but not in the control group. The difference between the two groups approached significance $(\mathrm{p}=0.064)$ only at follow-up (24 weeks) (table 4).

The 6MWD improved in both groups at all evaluations, but significantly more so for the intervention group than for the control group (table 5). For the latter, the improvement at 24 weeks was not statistically different from zero $(\mathrm{p}=0.11)$.

None of the changes in the respiratory or circulatory variables approached significance. There were no significant changes in tobacco consumption or in the expired carbon monoxide levels in either group. Six of the eight smoking patients in the intervention group wished to stop smoking, but none of them succeeded. The average number of exacerbations per patient was similar: intervention group 1.3 and control group 1.5.

Table 2. - Improvement in the Activities of Daily Living (ADL) score in the two groups studied

\begin{tabular}{lccc}
\hline & \multicolumn{3}{c}{ ADL score } \\
& Week 6 & Week 12 & Week 24 \\
\hline Control group & $-7.4 \pm 10.6$ & $-4.4 \pm 4.1$ & $-9.8 \pm 6.7$ \\
Treatment group & $6.2 \pm 2.8$ & $17.7 \pm 5.6$ & $14.4 \pm 4.7$ \\
p-value & 0.086 & 0.004 & 0.007 \\
\hline
\end{tabular}

Values are presented as mean \pm SEM.

Table 3. - Improvement in the Chronic Respiratory Disease Questionnaire (CRDQ) score in the two groups studied

\begin{tabular}{lccc}
\hline & \multicolumn{3}{c}{ CRDQ score } \\
& Week 6 & Week 12 & Week 24 \\
\hline Control group & $-0.2 \pm 3.8$ & $0.6 \pm 3.8$ & $-5.8 \pm 4.9$ \\
Treatment group & $6.6 \pm 3.1$ & $8.6 \pm 3.5$ & $11.1 \pm 4.5$ \\
p-value & 0.174 & 0.133 & 0.018 \\
\hline
\end{tabular}

Values are presented as mean \pm SEM.

Table 4. - Improvement in the York Quality of Life Questionnaire (YQLQ) score in the two groups studied

\begin{tabular}{lccc}
\hline & \multicolumn{3}{c}{ YQLQ score } \\
& Week 6 & Week 12 & Week 24 \\
\hline Control group & $-7.8 \pm 9.3$ & $-4.1 \pm 9.2$ & $-10.5 \pm 11.8$ \\
Treatment group & $-4.7 \pm 13.1$ & $26.4 \pm 17.3$ & $18.0 \pm 8.7$ \\
p-value & 0.458 & 0.171 & 0.064
\end{tabular}

Values are presented as mean \pm SEM.

Table 5. - Improvement in 6 min walking distance in the two groups studied

\begin{tabular}{lccc}
\hline & \multicolumn{3}{c}{6 min walking distance $\mathrm{m}$} \\
& Week 6 & Week 12 & Week 24 \\
\hline Control group & $21.6 \pm 9.9$ & $36.1 \pm 10.4$ & $21.4 \pm 13.4$ \\
Treatment group & $79.8 \pm 15.5$ & $113.1 \pm 17.8$ & $96.2 \pm 16.1$ \\
p-value & 0.004 & 0.001 & 0.001 \\
\hline
\end{tabular}

Values are presented as mean \pm SEM. 
Table 6. - Correlation matrix for the six main outcomes studied

\begin{tabular}{lcccccc}
\hline Variable & FEV1 & FVC & 6MWD & ADL & CRDQ & YQLQ \\
\hline FEV1 & - & 0.391 & 0.234 & 0.162 & 0.047 & -0.300 \\
FVC & 0.308 & - & 0.301 & 0.012 & 0.142 & 0.125 \\
6MWD & 0.008 & 0.391 & - & $0.720^{* *}$ & 0.430 & 0.414 \\
ADL & 0.318 & -0.316 & $0.636^{* *}$ & - & 0.376 & $0.563^{*}$ \\
CRDQ & 0.169 & -0.000 & 0.180 & 0.062 & - & $0.549^{*}$ \\
YQLQ & -0.484 & -0.031 & -0.002 & 0.439 & 0.000 & -
\end{tabular}

Values in the lower left triangle of the table are the partial correlation coefficients of 4th order, whilst those in the upper right triangle are the overall or 0th order correlation coefficients. FEV1: forced expiratory volume in one second; FVC: forced vital capacity; 6MWD: 6 min walking distance; ADL: Activities of Daily Living score; CRDQ: Chronic Respiratory Disease Questionnaire score; YQLQ: York Quality of Life Questionnaire score. *: $\mathrm{p}<0.05$; **: $\mathrm{p}<0.01$.

A total of 124 staff-hours were required, as follows: physician $16 \mathrm{~h}$ (teaching); nurse $9 \mathrm{~h}$ (teaching); physiotherapist $42 \mathrm{~h}$; auxilliary nurse $42 \mathrm{~h}$; occupational therapist $12 \mathrm{~h}$; psychologist $1 \mathrm{~h}$; dietician $1 \mathrm{~h}$; social worker $1 \mathrm{~h}$.

From the correlation matrix, only ADL and 6MWD showed significant partial correlation, while the correlation between FEV1 and YQLQ came close to significance. ADL and 6MWD, ADL and YQLQ, and YQLQ and CRDQ showed significant overall correlation (table 6).

\section{Discussion}

The main outcome variables of the present study were activities of daily living, quality of life, exercise tolerance and spirometry. Positive effects of the rehabilitation programme were found in the first three variables.

The ADL questionnaire was specifically designed for patients with COPD [15]. The improvements in ADL score are likely to be associated with the improvement of exercise tolerance, as the improvements were mainly in the more strenuous tasks (cleaning, shopping and personal care), and significant partial correlation was found between ADL and 6MWD (table 6). Further improvements are, therefore, unlikely to be obtained by upgrading the occupational therapy component of the programme. DeKHUIJZEN et al. [18] found that the ADL score improved in the training group, and that it correlated to well-being. The present results show that this correlation may be the product of simultaneous covariations with other variables (provided that the YQLQ score reflects general well-being) (table 6). Reduced anxiety and depression and improved psychological wellbeing, as reflected in the improved CRDQ score, might also have contributed to the positive effect of the rehabilitation programme on the ADL score $[18,19]$.

The CRDQ has been shown to be a responsive and valid measure of quality of life for patients with COPD [20], following rehabilitation programmes [21]. WIJKSTRA et al. [22] found that the dyspnoea quality of CRDQ had a low internal consistency but, in keeping with the other three qualities, dyspnoea also showed significant test/retest reliability. In a study design like the present, test/retest reliability is more important than internal consistency.

WiJKSTRA et al. [22] also sought to validate their use of the CRDQ in a Dutch population by comparing it to the Symptoms Check List (SCL-90), a score having nine qualities, each scored on a five point scale.
They found significant correlation between the qualities of the CRDQ and some of those of the SCL-90. Culturally and socioeconomically, Dutch and Danish populations might be very similar, but we nevertheless sought to validate the use of the translated questionnaires in a Danish population by calculating the correlations between the outcome measures, as shown in table 6. Like JonEs et al. [23], we did not find any correlation between 6MWD, quality of life and spirometry, thus confirming a common clinical observation. The 6MWD and ADL score showed the largest partial correlation, indicating that these two variables measure related aspects of daily functioning.

In the present study, the rehabilitation programme was associated with significant improvement of the CRDQ score at 24 weeks for the intervention group. Since the activities scored by the CRDQ and the ADL are those most severely affected by the disease, the effects of the rehabilitation programme on these scores substantiate its positive impact on everyday life for these patients.

This finding agrees with that of GoLDSTEIN et al. [24], who, in a controlled study in a patient population comparable to that of the present study, found improvement of three of the four qualities of the CRDQ. Unlike the present study, where the improvement at follow-up after 24 weeks supports the credibility of the improvements, their study did not evaluate any possible lasting effect of the rehabilitation. That programme was a combined in- and out-patient programme ( 8 weeks and 4 months, respectively) of a longer overall duration; thus, it must have been considerably more expensive and, as the benefits were similar, have a lower cost/benefit ratio than the present programme. WIJKSTRA et al. [25] studied the effects of a rehabilitation programme, in which the patients trained at home under the guidance of the primary care physician, a nurse and a physiotherapist. They found improvement in three of the qualities of the CRDQ, findings similar to those of GoLDSTEIN et al. [24] and the present study. The number of man-hours required for their rehabilitation programme was not reported, and, therefore, the cost/benefit ratio of their study and the present study cannot be compared.

The changes in the YQLQ score were all nonsignificant, with no significant differences between the treatment and control groups. Both patient groups, however, showed high values at inclusion, leaving little room for improvement. Such high values in patients with severe functional impairment are most likely due to the fact that the questionnaire includes many sedentary activities and 
is thus insensitive for monitoring rehabilitation, as suggested by JONES et al. [23].

In previous studies, the 6MWD has been shown to be reproducible $[1,26]$ and sensitive to changes in functional status during rehabilitation [27]. Upon repeated testing, a learning effect can be found as the distance improved between the first and second trial only [27]. The lack of practice trials in the present study can explain the improvements of 6MWD in the control group (table 5), which were barely significant at 6 weeks ( $\mathrm{p}=$ $0.05)$, significant at 12 weeks $(\mathrm{p}=0.04)$, and nonsignificant at 24 weeks $(\mathrm{p}=0.11)$. The improved 6MWD for the treatment group agrees with several earlier studies $[4,24,25,28]$. The mean improvement in 6MWD in the present study is approximately $33 \%$, which is larger than the improvements reported in other studies. The improvement declined progressively over 12 months in the study by SwERTs et al. [4], most likely because their patients discontinued the training at home, whilst the improvement in the study by Toshima et al. [28] and the present study persisted after 6 and 3 months, respectively. Thus, the latter two programmes may have succeeded in motivating the patients to continue training at home, indicating an important long-term effect of the programmes. In the present study, further improvements were small after 6 weeks, suggesting that a shorter programme than used in this study would suffice, as recently suggested by the European Respiratory Society (ERS) Task Force Position Paper [29].

Our training programme included both upper and lower limb exercise, as previous opinion was that any training effect obtained was likely to be specific for the muscle group trained, with no cross-over benefit [30]. Evidence to the contrary has, however, appeared [31]. It has previously been postulated that the improved functional capacity following training in COPD patients could be due to improved co-ordination and economy of motion, as they might be unable to exercise strenuously enough to achieve a training effect [32, 33]. However, other studies have shown that training can raise the anaerobic threshold in these patients [34-36], and this, with or without an increase in the maximal oxygen consumption, might explain the improvement in 6MWD in the present study, as our training programme was intensive and took the patients to their current limits. Despite that, the programme was well-tolerated and had a low drop-out rate.

In conclusion, our study shows that an economical, comprehensive, and well-tolerated rehabilitation programme can improve activities of daily living, quality of life, and functional capacity in patients with moderate-to-severe chronic obstructive pulmonary disease. The positive effect was apparent as early as 6 weeks after the beginning of the programme and persisted throughout the study. The modest personnel and economic requirements of the programme make it suitable for the maj-ority of hospitals. All the elements of our programme are currently in the European Respiratory Society Task Force Position Paper [29], except for the occupational therapy sessions, which may have been an important factor in the improvement of the Activities of Daily Living scores reported in the present study and would therefore, in our opinion, be worth considering for inclusion, as recently recommended [37].
Acknowledgements: The authors thank M. Axelsen (Registered Nurse), T. Clausen (Physiotherapist), J. Krause (Registered Nurse), B. Thermansen (Auxilliary Nurse). the late L. Lambertsen (Social Worker), D. Lodberg (Occupational Therapist), V. Petersen (Dietician), and I. Svennild (Clinical Psychologist), for their enthusiastic participation, without which the study could not have been completed.

\section{References}

1. Guyatt GH, Thompson PJ, Berman LB, et al. How should we measure function in patients with chronic heart and lung disease? J Chronic Dis 1985; 38 (6): 517-524.

2. Make BJ. Introduction to pulmonary rehabilitation. Clin Chest Med 1986; 7: 519-540.

3. Hudson LP, Tyler ML, Petty TL. Hospitalisation needs during an out-patient rehabilitation program for severe chronic airway obstruction. Chest 1976; 70: 606-610.

4. Swerts P, Kretzers L, Terpstra-Lindeman E, Verstappen F, Wouters E. Exercise reconditioning in the rehabilitation of patients with chronic obstructive pulmonary diseases: a short- and long-term analysis. Arch Phys Med Rehabil 1990; 71: 570-573.

5. Littlejohns P, Baveystock CM, Parnell H, Jones PW. Randomized, controlled trial of the effectiveness of a respiratory health worker in reducing impairment, disability, and handicap due to chronic airflow limitation. Thorax 1991; 46: 559-564.

6. Sinclair DJM, Ingram CG. Controlled trial of supervised exercise in chronic bronchitis. Br Med J 1980; 1: 519-521.

7. Cockroft GH, Saunders MJ, Berry G. Randomized, controlled study of rehabilitation in chronic respiratory disability. Thorax 1981; 36: 200-203.

8. McGavin CR, Gupta SP, Lloyd EL, McHardy JR. Physical rehabilitation for the chronic bronchitic: results of a controlled trial of exercises in the home. Thorax 1977; 32: 307-311.

9. Strijbos JH, Koëter GH, Meinesz AF. Home care rehabilitation and perception of dyspnea in chronic obstructive pulmonary disease (COPD) patients. Chest 1990; 97: $109 \mathrm{~s}-110 \mathrm{~s}$.

10. Ries AL, Moster KM. Comparison of isocapnic hyperventilation and walking exercise training at home in pulmonary rehabilitation. Chest 1986; 90: 285-289.

11. Reardon J, Awad E, Normandine E, Vale F, Clark B, ZuWallack RL. The effect of comprehensive pulmonary rehabilitation on dyspnea. Chest 1994; 105: 10461052.

12. Quanjer PH, Tammeling GJ, Cotes JE, Pedersen OF, Peslin R, Yernault JC. Lung volumes and forced ventilatory flows. Report Working Party. Standardization of Lung Function Tests. Official Statement of the European Respiratory Society. Eur Respir J 1994; 6: Suppl. 16, 5-40.

13. Tønnesen P, Nørregård J, Simonsen K, Säwe U. A double-blind trial of 16 hour transdermal nicotine patch in smoking cessation. N Engl J Med 1991; 325: 311-315.

14. Transdermal Nicotine Study Group. Transdermal nicotine for smoking cessation: six month results from two multicenter controlled clinical trials. JAMA 1991; 266: 3133-3138.

15. Ogden LD, Derenne C. Chronic obstructive pulmonary disease: program guidelines for occupational therapists and other health professionals. Laurel, Maryland, Ramsco Publishing, 1985. 
16. Guyatt GH, Berman LB, Townsend M, Pugsley S, Chambers LW. A measure of quality of life for clinical trials in chronic lung disease. Thorax 1987; 42: 773778.

17. Gudex C, Kind P. The QALY Toolkit. Discussion Paper 38. York, Centre for Health Economics, University of York, 1988.

18. Dekhuijzen PNR, Beek MML, Folgering HTM, van Herwaarden CLA. Psychological changes during pulmonary rehabilitation and target-flow inspiratory muscle training in COPD patients with a ventilatory limitation during exercise. Int J Rehabil Res 1990; 13: 109-117.

19. Cockroft A, Berry G, Brown EB, Exall C. Psychological changes during a controlled trial of rehabilitation in chronic respiratory disability. Thorax 1982; 37: 413416.

20. Guyatt GH, Townsend M, Keller J, Singer J, Nogradi $\mathrm{S}$. Measuring functional status in chronic lung disease: conclusions from a randomized, controlled trial. Respir Med 1989; 83: 293-297.

21. Lacasse Y, Wong E, Guyatt GH, King D, Cook DJ, Goldstein S. Meta-analysis of respiratory rehabilitation in chronic obstructive pulmonary disease. Lancet 1996; 348: 1115-1119.

22. Wijkstra PJ, TenVergert EM, van Altena R, et al. Reliability and validity of the Chronic Respiratory Questionnaire (CRQ). Thorax 1994; 49: 465-467.

23. Jones PW, Quirk FH, Baveystock CM, Littlejohns P. A self-complete measure of health status for chronic airflow limitation. Am Rev Respir Dis 1992; 145: 13211327.

24. Goldstein RS, Gort EH, Stubbing D, Avendano MA, Guyatt GH. Randomized controlled trial of respiratory rehabilitation. Lancet 1994; 344: 1394-1397.

25. Wijkstra PJ, van Altena R, Kraan J, Otten V, Postma DS, Koëter GH. Quality of life in patients with chronic obstructive pulmonary disease improves after rehabilitation at home. Eur Respir J 1994; 7: 269-273.

26. Noseda A, Carpiaux JP, Progogine T. Lung function, maximum and submaximum exercise testing in COPD patients: reproducibility over a long interval. Lung 1989; 167: 247-257.

27. McGavin CR, Gupta SP, McHardy GJR. Twelve minute walking test for assessing disability in chronic bronchitis. Br Med J 1976; 1: 822-823.

28. Toshima MT, Kaplan RM, Ries AL. Experimental evaluation of rehabilitation in chronic obstructive pulmonary disease: short-term effects on exercise endurance and health status. Health Psychol 1990; 9(3): 237-252.

29. ERS Task Force Position Paper. Selection criteria and programmes for pulmonary rehabilitation in COPD patients. Eur Respir J 1997; 10: 744-757.

30. Lake FR, Henderson K, Briffa T, Openshaw J, Musk W. Upper limb and lower limb exercise training in patients with chronic airflow obstruction. Chest 1990; 97(5): 1077-1082.

31. Clark CJ, Cochrane L, Mackay E. Low intensity peripheral muscle conditioning improves exercise tolerance and breathlessness in COPD. Eur Respir J 1996; 9: 25902596.

32. Hughes RL, Davison R. Limitations of exercise reconditioning in COLD. Chest 1983; 2: 241-249.

33. Cockroft A. Pulmonary rehabilitation. Br J Dis Chest 1988; 82: 220-225.

34. Carter R, Coast JR, Idell S. Exercise training in patients with chronic obstructive pulmonary disease. Med Sci Sports Exerc 1992; 24(3): 281-291.

35. Casaburi R, Wasserman K, Patessio A, Ioli F, Zanaboni $\mathrm{S}$, Donner CF. A new perspective in pulmonary rehabilitation: anaerobic threshold as a discriminant in training. Eur Respir J 1989; 2 (Suppl. 7): 618s-623s.

36. Casaburi R, Patessio A, Ioli F, Zanaboni S, Donner CF, Wasserman K. Reduction in exercise lactic acidosis and ventilation as a result of exercise training in patients with obstructive pulmonary lung disease. Am Rev Respir Dis 1991; 143: 9-18.

37. Clark CJ. Is pulmonary rehabilitation effective for patients with COPD? Lancet 1996; 348: 1111-1112. 